\title{
Editorial
}

\section{Editorial: Arthroplasty Devices: Registries and Beyond}

\author{
Yelizaveta Torosyan MD, PhD, Steven M. Kurtz PhD, \\ William M. Mihalko MD, PhD, Danica Marinac-Dabic MD, PhD, \\ Clare M. Rimnac PhD
}

I $\mathrm{n}$ spite of the overall technological progress and clinical success of orthopaedic devices, unexpected safety concerns, such as those reported for some metal-on-metal (MoM) total hip replacements [2], continue to attract substantial attention from patients, physicians, and policy makers. Recently, CORR $^{\circledR}$, s Editor-inChief suggested that it can be "difficult to resist the lure of new technologies." [3]. Indeed, the current healthcare environment in the United States is such that the early adoption of new technologies

The authors certifies that they, or any members of their immediate families, have no commercial associations (eg, consultancies, stock ownership, equity interest, patent/ licensing arrangements, etc) that might pose a conflict of interest in connection with the submitted article.

All ICMJE Conflict of Interest Forms for authors and Clinical Orthopaedics and Related Research ${ }^{\mathbb{B}}$ editors and board members are on file with the publication and can be viewed on request.

The opinions expressed are those of the writers, and do not reflect the opinion or policy of $C O R R^{\circledR}$ or the Association of Bone and Joint Surgeons ${ }^{\circledR}$.

Y. Torosyan MD, $\mathrm{PhD}$,

D. Marinac-Dabic MD, $\mathrm{PhD}$

Division of Epidemiology, Office of

Surveillance and Biometrics, Center for

Devices and Radiological Health,

CDRH/FDA, Silver Spring, MD, USA may be difficult to resist, and introducing new devices into a complicated biological milieu like the human body will always be complicated and, to some degree, uncertain.

Established international registries such as those implemented in Australia [1], as well as in England and Wales [4], effectively monitor both the successes and the problems associated with newly introduced implants. Similarly, the establishment of the International Consortium of Orthopedic Registries, consisting of 29 international registries with information covering more than 3.6 million orthopaedic implants, represents an

S. M. Kurtz PhD

Implant Research Center, Drexel

University, Philadelphia, PA, USA

W. M. Mihalko MD, PhD

Campbell Clinic Department of

Orthopaedic Surgery and Biomedical

Engineering, University of Tennessee,

Memphis, TN, USA

C. M. Rimnac $\mathrm{PhD}$

Case School of Engineering, Case

Western Reserve University, Cleveland, $\mathrm{OH}$, USA

C. M. Rimnac PhD ( $)$

Clinical Orthopaedics and Related

Research, Philadelphia, PA 19103, USA

e-mail: crimnac@clinOrthop.org unprecedented effort to collate this information into an even more effective resource. In the United States, the FDA is working on advances that will more effectively employ registries to better understand in vivo device performance [7]. Certainly, the current and developing orthopaedic registries in the United States are becoming a valuable resource containing clinical documentation about the performance of specific devices and technologies in definable patient populations. However, recent recalls related to certain MoM hip implants [9] suggest there are important limitations associated with the current approaches to arthroplasty-related data gathering and analysis. While registries record some information - for example, they distinguish between aseptic loosening and loosening from infection - they generally are silent on the mechanisms of failure beyond that. And as we have seen recently, particularly with the MoM failures, we must come to understand these mechanisms. Inconsistent and confusing terminology further frustrates our efforts; for example, soft-tissue changes in response to metal interactions may be described using a variety of terms, including "metallosis", "pseudotumors", "adverse local tissue reaction", 
"aseptic lymphocyte-dominated vasculitis-associated lesion", and "adverse reaction to metal debris".

There is a clinical and regulatory need, but also an unprecedented opportunity, for further development of national and international initiatives aimed at capturing and synthesizing interdisciplinary (clinical, biological, technological) evidence for more comprehensive analysis of the causes pertaining to orthopaedic revision burden. Along with the US national registries, the FDA is a key partner in this multidisciplinary effort. The FDA's Center for Devices and Radiological Health (CDRH), where two of the authors work (YT, DM-D), has taken on this challenge, consistent with the CDRH goals of facilitating medical device innovation through the advancement of regulatory science and providing our industry with reliable and efficient regulatory pathways [6].

To expand the evidentiary capabilities provided by registries, we need further evidence on device performance that incorporates higher-level data derived from in vitro biocompatibility testing, radiographic monitoring, and appropriate explant and periprosthetic tissue analysis.

Explant retrieval analysis, for example, remains one of the mostimportant sources of ex vivo evidence that can support a deeper understand- ing of the safety and effectiveness of established implant technologies and delineate the steps to minimize possible failure. Meta-analyses that characterize both the extent of device alterations (physical, mechanical, chemical), as well as the extent of the biological response (eg, periprosthetic tissue necrosis and inflammation), are necessary to understand in a comprehensive way the factors that determine an implant's clinical success or failure. However, registries cannot provide this information, which is so necessary to understand fully the in vivo success and failure patterns of today's arthroplasty devices.

Evidence synthesis from a variety of sources into a robust clinical and regulatory framework could allow innovation to occur in such a way that genuine improvements can be delivered to patients, while protecting patients from unintended and sometimes severe consequences. As one part of the solution to address the evidentiary challenges and needs, the $\mathrm{CDRH}$ is developing revised guidance documents on the use of biomaterialsand device-related standards and clinical outcomes with input from the clinical, research, and industrial communities. For example, the $\mathrm{CDRH}$ is currently working on a scientificallyvalidated Medical Device Development Tools program [8] that can incorporate clinical outcomes, markerbased tests, analytic assays, imaging methods, and nonclinical assessments based on predictive modeling. Taken together, these approaches seek to advance the assessment of medical devices, including joint replacements. This ideally will be achieved in a manner that does not result in increased cost or delays in introducing new technology or which could lead to other industry disincentives due to over-regulation.

How can the orthopaedic community participate in this effort? For these new approaches to be successful, the US registry movement needs to be broadly implemented by hospitals across the country. Well-functioning registries are fundamental to the goals of the orthopaedic community [5]. However, we also need new partnerships and an integrated infrastructure to enable the successful incorporation of clinical and imaging data and the results of biocompatibility testing and retrieval analysis into a more comprehensive process of implant evaluation. Presently, numerous legal and regulatory challenges impede the establishment of such multi-institutional orthopaedic efforts. For example, hospitals discard most retrieved tissues and devices collected at revision surgery after routine pathological examination. The orthopaedic 
community can support regional and national orthopaedic registries by directly supporting device and tissue retrieval and analysis as well as by participating in other registry-based research efforts. By extension, researchers need to make their findings accessible by creating shared data sources and discussing their clinical applicability at orthopaedic forums so that their data can be readily available to and actionable by the surgeons and wider orthopaedic community.

Ultimately, research data for explanted devices and tissues need to be directly linked to the device/patient records in national registries. Such registry-based networks will serve as the basis for a new evidence-gathering approach, which begins with implant design, and continues to track device performance throughout its lifetime or the lifetime of the patient. As a result, better designed epidemiological studies will be enabled by translational research findings and will be performed via well-functioning national registries linked to complementary sources of multidisciplinary evidence.

\section{References}

1. Australian Orthopaedic Association National Joint Replacement Registry. Annual Report. 2013. Available at: http://www.dmac.adelaide.edu.au/aoa njrr/publications.jsp. Accessed October 17, 2014.

2. Langton DJ, Jameson SS, Joyce TJ, Gandhi JN, Sidaginamale R, Mereddy P, Lord J, Nargol AV. Accelerating failure rate of the ASR total hip replacement. J Bone Joint Surg Br. 2011;93:1011-1016.

3. Leopold SS. Editorial: Our love affair with technology and the choices we make. Clin Orthop Relat Res. 2014;472:2907-2908.

4. National Joint Registry. The 10th annual report of the National Joint Registry for England, Wales and Northern Ireland. 2013. Available at: http://www.njrcentre.org.uk/njrcentre/AbouttheNJR/Publicationsandreports/Annualreports/Arc hivedannualreports/tabid/87/Default. aspx. Accessed October 17, 2014.

5. Sedrakyan A, Paxton EW, MarinacDabic D. Stages and tools for multinational collaboration: the perspective from the coordinating center of the International Consortium of Orthopaedic Registries (ICOR). J Bone Joint Surg Am. 2011;93 Suppl 3:76-80.
6. United States Food and Drug Administration. About the center for devices and radiological health. Available at: http://www.fda.gov/AboutFDA/CentersOffices/OfficeofMedicalProductsandTobacco/CDRH/. Accessed September 6, 2014.

7. United States Food and Drug Administration, Center for Devices and Radiological Health. Strengthening our national system for medical device postmarket surveillance; Update and next steps. April 2013. Available at: http://www.fda.gov/down loads/MedicalDevices/Safety/CDRH PostmarketSurveillance/UCM348845. pdf; Accessed Sep 15, 2014.

8. United States Food and Drug Administration. Medical device development tools. Available at: http://www.fda.gov/MedicalDevices/ScienceandResearch/MedicalDeviceDevelopmentToolsMDDT/default.html. Accessed October 17, 2014.

9. United States Food and Drug Administration. Recalls specific to metal-onmetal hip implants. http://www.fda.gov/medicaldevices/productsandmedi calprocedures/implantsandprosthetics/ metalonmetalhipimplants/ucm241770. htm. 2014; Accessed September 6, 2014. 